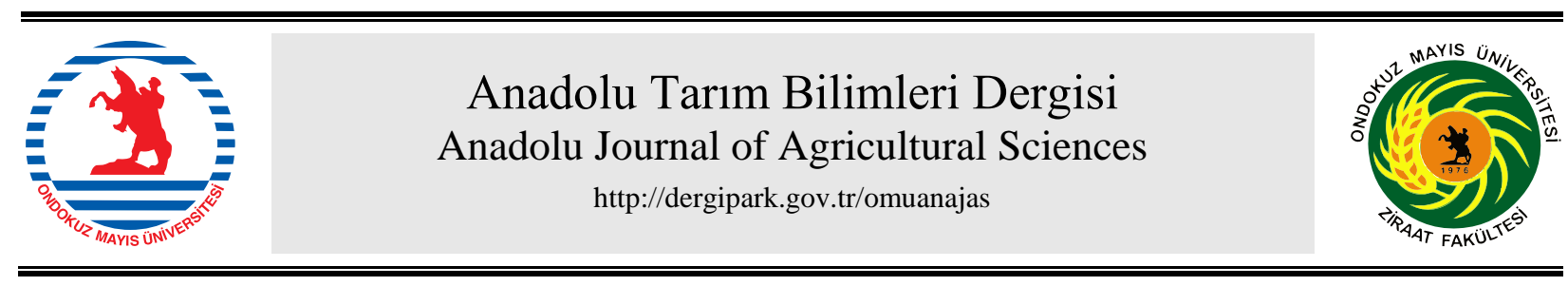

\section{Araş̧tırma/Research}

Anadolu Tarım Bilim. Derg./Anadolu J Agr Sci, 34 (2019) ISSN: 1308-8750 (Print) 1308-8769 (Online) doi: $10.7161 /$ omuanajas. 444180

\title{
Farklı gelişim dönemlerinde çiçek tomurcuğu almanın Muscari armeniacum Leichtlin ex Baker'in soğan ve bitki gelişimi üzerine etkileri
}

\author{
Özgür Kahraman \\ Çanakkale Onsekiz Mart Üniversitesi, Mimarlık ve Tasarım Fakültesi Peyzaj Mimarlı̆̆ı Bölümü, Çanakkale \\ Sorumlu yazar/corresponding author: ozgurkahraman@comu.edu.tr
}

Geliş/Received 16/07/2018～Kabul/Accepted 05/12/2018

\begin{abstract}
ÖZET
Türkiye'nin büyük bir bölümünde doğal yayılış gösteren üzüm sümbülü (Muscari armeniacum Leichtlin ex Baker), Liliaceae familyasına bağlı soğanlı bitkilerden birisidir. Soğanlarının çiçek açabilmesi için belli bir çevre uzunluğunda olması gerekir. Bu çalışma; farklı gelişim dönemlerinde çiçek tomurcuğu alma uygulamalarının üzüm sümbülü gelişimi üzerine etkilerini saptamak için Aralık 2015-Mayıs 2016 tarihleri arasında yürütülmüştür. Bitkisel materyal olarak $7.5 \mathrm{~cm}$ çevre uzunluğundaki üzüm sümbülü soğanlarının kullanıldığı çalışma, saksı kültüründe yürütülmüş ve yetiştirme ortamı olarak torf + perlit $(1: 1 ; \mathrm{v} / \mathrm{v})$ karışımı kullanılmıştır. Çalışmada; çıkışta çiçek tomurcuğu alma (D1), çiçek açmadan çiçek tomurcuğu alma (D2) ve kontol (K) olmak üzere 3 farklı gelişim döneminde çiçek tomurcuğu alma işlemi uygulanmıștır. Denemede; bitki ağırlığı, soğan çapı, yavru soğan sayısı, yaprak sayısı, yaprak uzunluğu, yaprak eni, yaprak kalınlığı, çiçek sapı uzunluğu, çiçek sapı çapı, çiçek salkım uzunluğu, salkımdaki çiçek sayısı ve çiçek salkım çapı incelenmiştir. Çiçek tomurcuğu alma uygulamalarının soğan çapı, yavru soğan sayısı, bitki ağırlığı, yaprak sayısı, yaprak uzunluğu, yaprak eni ve yaprak kalınlığı üzerine etkisi istatistiksel olarak önemsiz bulunmuștur. Soğan çapı değerleri $32.52 \mathrm{~mm}$ (D1), $32.87 \mathrm{~mm}$ (D2) ve $31.29 \mathrm{~mm}$ (K) olmuştur. Yavru soğan sayıs1 4.96 adet (K) ile 6.06 adet (D2) arasında, yaprak uzunluğu $49.59 \mathrm{~cm}$ (D2) ile $50.93 \mathrm{~cm}$ (D1) arasında değişmiştir. Soğan çapı ve yavru soğan sayısı yönünden uç alma yapılan uygulamalarda daha yüksek değerler elde edilmiştir.
\end{abstract}

The effects of plucking flower bud on bulb and plant growth of Muscari armeniacum Leichtlin ex Baker in different developmental periods

\begin{abstract}
Grape hyacinth (Muscari armeniacum Leichtlin ex Baker) is one of bulbous plants natural distributed in a large part of Turkey. Grape hyacinth belongs to Liliaceae family. Grape hyacinth bulbs must be in a certain circumference to be able to blossom. This study was conducted between December 2015 and May 2016 to determine the effects of plucking flower bud on grape hyacinth growing in different developmental periods. Grape hyacinth bulbs with a circumference of $7.5 \mathrm{~cm}$ were used as plant material. Peat + perlite $(1: 1 ; \mathrm{v} / \mathrm{v})$ mixture was used as a growing media. The study was conducted in pot culture. In the study, flower bud was plucked in 3 different developmental periods. The flower bud was plucked as soon as it was seen in first treatment (D1). The flower bud was plucked under its receptacle before blooming in second treatment (D2). The flower bud was not plucked in the control (K). Plant weight, bulb diameter, bulblet number, leaf number, leaf length, leaf width, leaf thickness, pedicle length, pedicle diameter, raceme length, flower number in raceme, raceme diameter parameters were examined in the trial. The effect of plucking flower bud on bulb diameter, bulblet number, plant weight, leaf number, leaf length, leaf width and leaf thickness was statistically insignificant. The values of the bulb diameter were $32.52 \mathrm{~mm}$ (D1), $32.87 \mathrm{~mm}$ (D2) and $31.29 \mathrm{~mm}(\mathrm{~K})$. The bulblet number ranged from $4.96(\mathrm{~K})$ to $6.06(\mathrm{D} 2)$, leaf length between $49.59 \mathrm{~cm}$ (D2) and $50.93 \mathrm{~cm}$ (D1). In the treatments
\end{abstract} where flower bud plucked, higher bulb diameter and bulblet number were obtained.
Anahtar Sözcükler: Muscari armeniacum Üzüm sümbülü Soğan Yavru soğan Süs bitkileri Yetiştiricilik
Keywords: Muscari armeniacum Grape hyacinth Bulb Bulblet Ornamental plant Cultivation

(C) OMU ANAJAS 2019 


\section{Giriş}

Türkiye bitki çeşitliği yönünden oldukça zengindir. Türkiye'de yaklaşık 12000 bitki taksonu yer almakta, bunlardan 3750 takson ise endemiktir (Avc1, 2005). 1056 takson soğanlı, rizomlu, yumrulu ve soğanımsı gövdeli (veya kormlu) bitki türü doğal yayılış göstermektedir. $\mathrm{Bu}$ taksonlardan 424'ü endemik, endemizm oranı ise \% 40'tır (Özhatay, 2013). Ülkemizde soğanlı, rizomlu, soğanımsı gövdeli ve yumrulu bitkilerin doğadan toplanması, üretimi ve ihracatı yönetmelikle kontrol edilmektedir. Muscari türlerinin hepsinin ihracatı "Doğal çiçek soğanlarının doğadan toplanması, üretimi ve ihracatına ilişkin yönetmelik" ve "Doğal çiçek soğanlarının 2018 yılı ihracat listesi hakkında tebliğ" ile yasaklanmıştır (Resmi Gazete 2017a; 2017b). Muscari armeniacum Leichtlin ex Baker türünün ihracatı da bu kapsam içerisindedir.

Muscari armeniacum Leichtlin ex Baker; üzüm sümbülü, gâvurbaşı ve Türk sümbülü isimleri ile tanınır. Türkiye'de İzmir, Aydın, Kütahya, Konya, Çanakkale, Antalya, İçel, Adana, Kahramanmaraş, Osmaniye, İstanbul, Ankara, Bolu, Kars, Ağrı, Erzincan, Gümüşhane, Amasya, Kayseri, Kocaeli, Rize, Sakarya, Sinop ve Sivas'ta doğal yayılış göstermektedir (Tübives, 2018). İngilizce Grape hyacinth ve Turkish hyacinth diye adlandırılır. Üzüm sümbülü Liliaceae familyasına bağlı çok yıllık, soğanlı otsu bir bitkidir. Yapraklar şerit şeklinde, uç kısmına doğru sivri, parlak yeşil ve kalındır. İlkbaharda yapraklar arasından çiçeklerini çıkarır. 10-20 cm çiçek sapı ucunda başak biçiminde çiçekleri toplanmıştır. Her bir çiçeği aşağı doğru sarkık, çan biçiminde mavi veya mor renklidir (Şekil 1). Güneşli ve yarıgölge yerleri sever. Ilıman ve nemli yerlerde yetişir. Humusca zengin, nemli, drenaj1 iyi, gevşsek topraklarda iyi gelişir. Bulunduğu yerde gelişerek yayılır. Soğanların birkaç yılda bir sökülerek, yeniden dikilmesi gerekir. Soğan ve yavru soğanları ile üretimi yapılır. (Yücel, 2002; Pamay, 2004). Soğanlarının çiçeklenebilmesi için soğan çevre uzunluğunun belli bir büyüklüğün üzerinde olmas1 gerekir. Yavru soğanlar ile üretim yapıldığında çiçek açabilecek soğan iriliğine ulaşması için 5-6 yıl gibi uzun bir sürenin geçmesi gerekmektedir. Bu süreyi kısaltmak için uygulanabilecek yöntemlerden birisi de çiçek tomurcuğunun koparılması işlemidir. Çiçek tomurcuğu alma uygulamasının soğan gelişimi üzerine pozitif etkisinin olduğu bazı çalışmalar bulunmaktadır. Kahraman (2016); çiçek tomurcuğu almanın beyaz zambak bitkisinin soğan gelişimi üzerine etkisini araştırdığı çalışmasında; çiçek tomurcuğunun oluşur oluşmaz koparılan bitkilerin soğan çapı, soğan ağırlığı ve gövde çapı değerlerinin çiçek tomurcuğu koparılmayan uygulamaya göre daha yüksek olduğunu belirtmiştir. Kahraman (2017); farklı aşamalarda çiçek sap1 almanın Tulipa gesneriana L. "Golden Parade" çeşidinin büyüme ve soğan gelişimini araştırdığı çalışmasında; en yüksek soğan çapını çiçek sapının çıkışta ve çiçeğinin açmadan koparıldığı uygulamalarda tespit etmiştir. Yavru soğan sayısı ve yavru soğan çap1 bakımından uygulamalar arasında istatiksel fark belirlememiştir.

$\mathrm{Bu}$ araştırma; farklı gelişim dönemlerinde çiçek tomurcuğu almanın üzüm sümbülü bitkisinin gelişim özellikleri üzerine etkilerini belirlemek için yürütülmüştür.

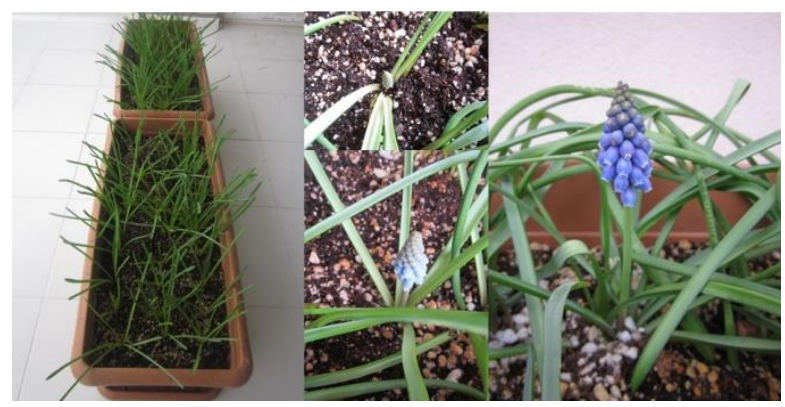

Şekil 1. Üzüm sümbülü bitkisinin gelişimi

\section{Materyal ve Yöntem}

Araştırma 13 Aralık 2015 ile 16 Mayıs 2016 tarihleri arasında Çanakkale Onsekiz Mart Üniversitesi, Terzioğlu Yerleşkesi’nde yer alan, Mimarlık ve Tasarım Fakültesi'ne ait açık alanda gerçekleştirilmiştir. Bitkisel materyal olarak $7.5 \mathrm{~cm}$ çevre uzunluğuna sahip Muscari armeniacum Leichtlin ex Baker (Üzüm sümbülü) soğanları kullanılmıştır (Şekil 2). Üzüm sümbülü soğanları Konya'nın Çumra ilçesinde çiçek soğanları üretimi yapan özel bir firmadan temin edilmiştir. Üzüm sümbülü soğanları mantari hastalıklara karşı dikim öncesi \% 1 Captan ve \% 0.5 Mancozeb solüsyonu içinde 20 dakika bekletilmiş, daha sonra soğanlardaki fazla ilaç solüsyonun süzülmesi için serin, gölge bir ortamda dikime kadar beklemeye alınmıştır.

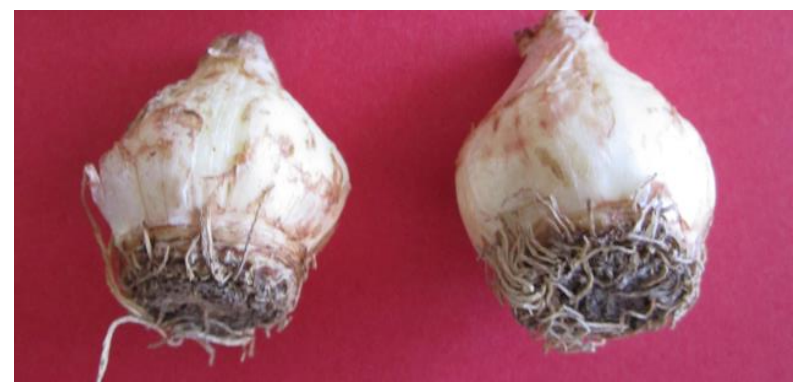

Şekil 2. Denemede kullanılan üzüm sümbülü soğanları

Deneme saksı kültüründe yürütülmüş ve yetiştirme kabı olarak 70x31x25 cm boyutlarındaki 38 litre hacme sahip saksılar (Şekil 3), yetiştirme ortamı olarak da perlit ve torfun hacimsel olarak 1:1 oranındaki karışımı kullanılmıştır. Saksıların içi üst kısmında $7 \mathrm{~cm}$ 'lik boşluk kalacak biçimde yetiştirme ortamı ile doldurulmuş ve üzüm sümbülü soğanları 13 Aralık 2015 tarihinde $10 \times 7 \mathrm{~cm}$ aralıklarla yetiştirme ortamı üzerine yerleştirilmiştir. Soğanların üzeri $7 \mathrm{~cm}$ kalınlığında yetiştirme ortamı (kapak) ilave edilerek dikim işlemi 
tamamlanmıştır (Şekil 3). Dikim sonrası soğanlara saksı altından su çıkana kadar sulama yapılmış, yă̆ı̧̧ durumuna göre sulama tekrar edilmiştir.

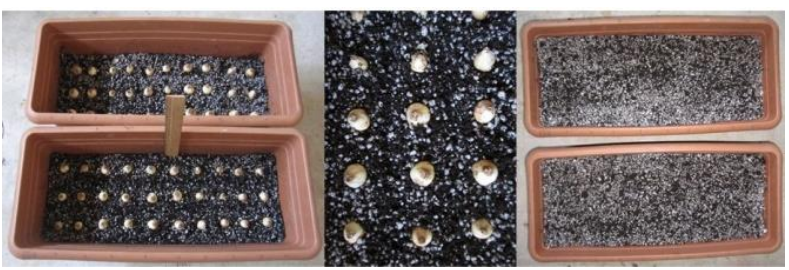

Şekil 3. Denemede kullanılan saksılar ve soğanların yetiştirme ortamına dikimi

Çiçek tomurcuğu almanın üzüm sümbülü gelişimindeki etkisini saptamak amacıyla üç farklı aşamada çiçek tomurcuğu alma uygulaması yapılmıştır (Şekil 4): Bunlar; 1) Çiçek tomurcuğunun toprak yüzeyine çıkışından hemen sonra çiçek sapının çiçek salkımı altından elle kırılması (D1), 2) Çiçek tomurcuğunun çiçek sap1 ve salkım oluşturup renk gösterdikten sonra çiçek sapının çiçek salkımının altından elle kirılmasi (D2), 3) Kontrol (K) uygulamasında çiçek tomurcuğuna herhangi bir işlem yapılmamış ve tomurcuk bitki üzerinde bırakılmıştır. Soğanların sökümü 16 Mayıs 2016 tarihinde gerçekleştirilmiştir.

Denemede; bitki ağırlığı, soğan çapı, yavru soğan sayıs1, yaprak sayısı, yaprak uzunluğu, yaprak eni,

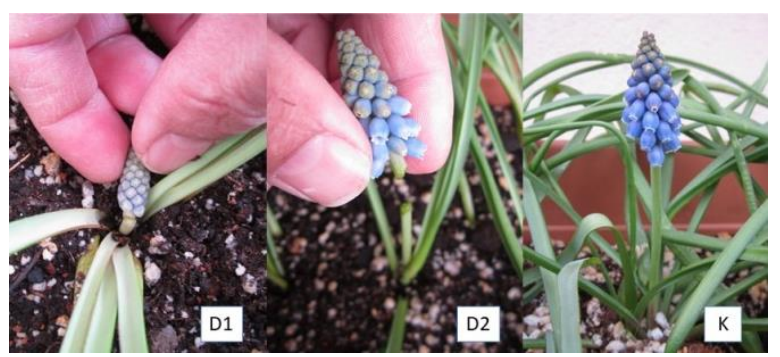

Şekil 4. Denemede uygulanan uç alma uygulamaları

yaprak kalınlığı, çiçek sap1 uzunluğu, çiçek sap1 çap1, çiçek salkım uzunluğu, salkımdaki çiçek sayısı ve çiçek salkım çapı parametreleri incelenmiştir. Elde edilen verilere SPSS 23 istatistik programı ile varyans analizi ve Pearson korelasyon testi uygulanmıştır. Deneme alanının sıcaklık (minimum, maksimum ve ortalama) ve ortalama nem verileri Çanakkale Meteoroloji İstasyonu'ndan temin edilmiştir.

\section{Bulgular ve Tartışma}

Deneme süresince, deneme alanının günlük minimum sicaklık $\left({ }^{\circ} \mathrm{C}\right)$, maksimum sicaklık $\left({ }^{\circ} \mathrm{C}\right)$, ortalama sicaklık $\left({ }^{\circ} \mathrm{C}\right)$ ve ortalama nem $(\%)$ değerleri Şekil 5.'de gösterildiği gibi oluşmuştur.

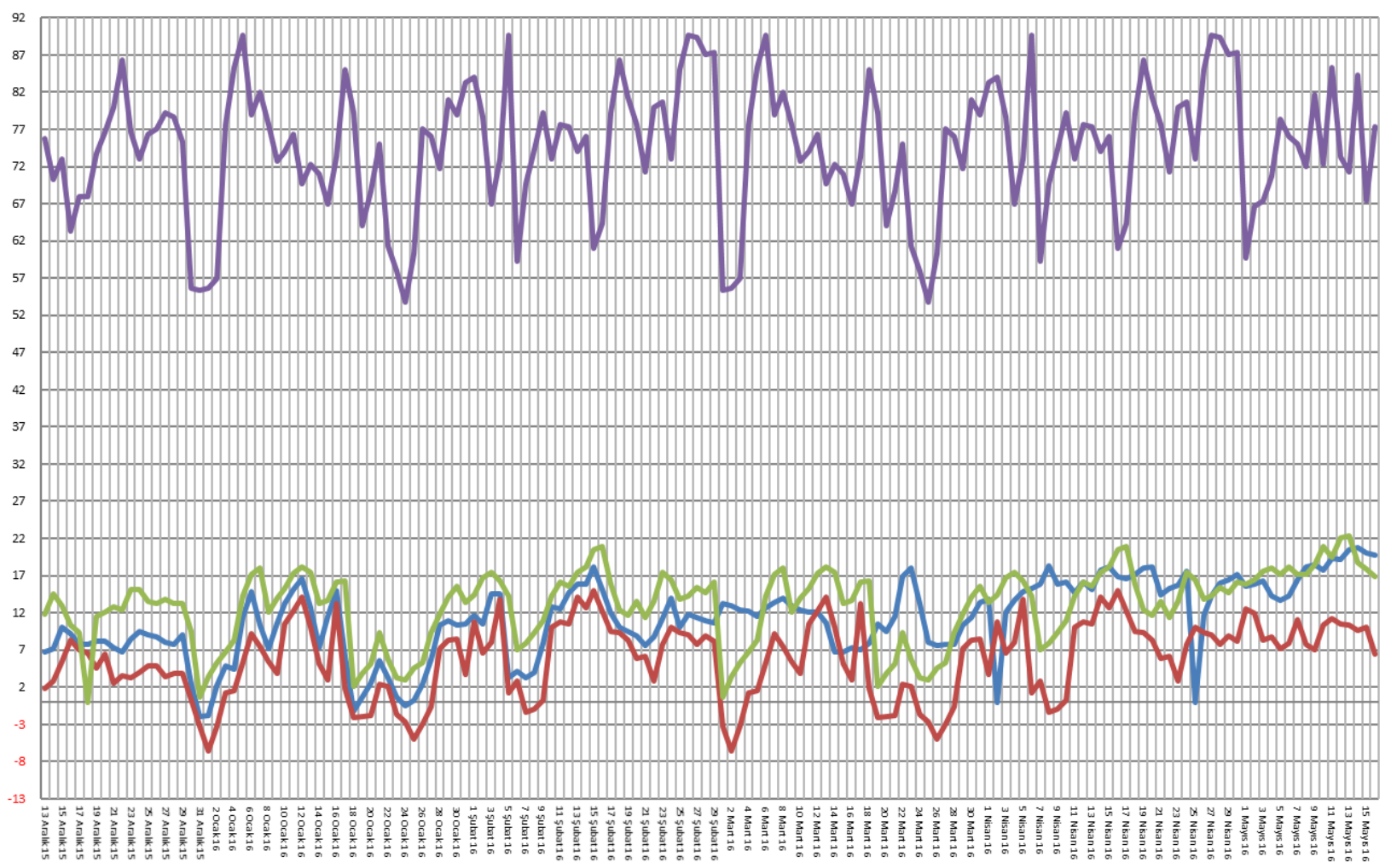

-Ortalama Sıcaklık (oC) - Minimum Sıcaklık (oC) —Maksimum Sıcaklık (oC) $\quad$ Ortalama Nem (\%)

Şekil 5. Deneme alanının günlük sıcaklık ve nem değerleri 
Deneme süresince, en düşük sicaklıklar 1 Ocak 2016 $\left(-6.5^{\circ} \mathrm{C}\right), 25$ Ocak $2016\left(-5^{\circ} \mathrm{C}\right), 2$ Mart $2016\left(-6.5^{\circ} \mathrm{C}\right)$ ve 26 Mart $2015\left(-5^{\circ} \mathrm{C}\right)$ tarihlerinde; en yüksek sicaklık değerleri ise 15 Şubat $2016\left(20.5^{\circ} \mathrm{C}\right), 16$ Şubat 2016 $\left(20.9{ }^{\circ} \mathrm{C}\right), 17$ Nisan $2016\left(20.9{ }^{\circ} \mathrm{C}\right), 10$ Mayis 2016 $\left(20.9^{\circ} \mathrm{C}\right), 12$ Mayıs $2016\left(22.1{ }^{\circ} \mathrm{C}\right)$ ve 13 Mayis 2016 $\left(22.3{ }^{\circ} \mathrm{C}\right)$ tarihlerinde gerçekleşmiştir. Bu sicaklık değerlerinin üzüm sümbülü gelişimi üzerinde olumsuz bir etkisi gözlenmemiştir. Ortalama nem değeri \% 53.7 ile 89.7 arasında değişmiştir. Bu sıcaklık değerlerinin üzüm sümbülü gelişimi üzerinde olumsuz bir etkisi gözlenmemiştir. Yapılan istatiksel analizler sonucunda farklı gelişme döneminde çiçek tomurcuğu alma uygulamalarının bitki ağırlığı, soğan çapı, soğan çapı artış oranı ve yavru soğan sayısı üzerine etkisi önemsiz bulunmuştur. Bitki ağırlı̆̆ değerleri $34.05 \mathrm{~g}$ ile $34.27 \mathrm{~g}$ arasında değişmiştir (Şekil 6).

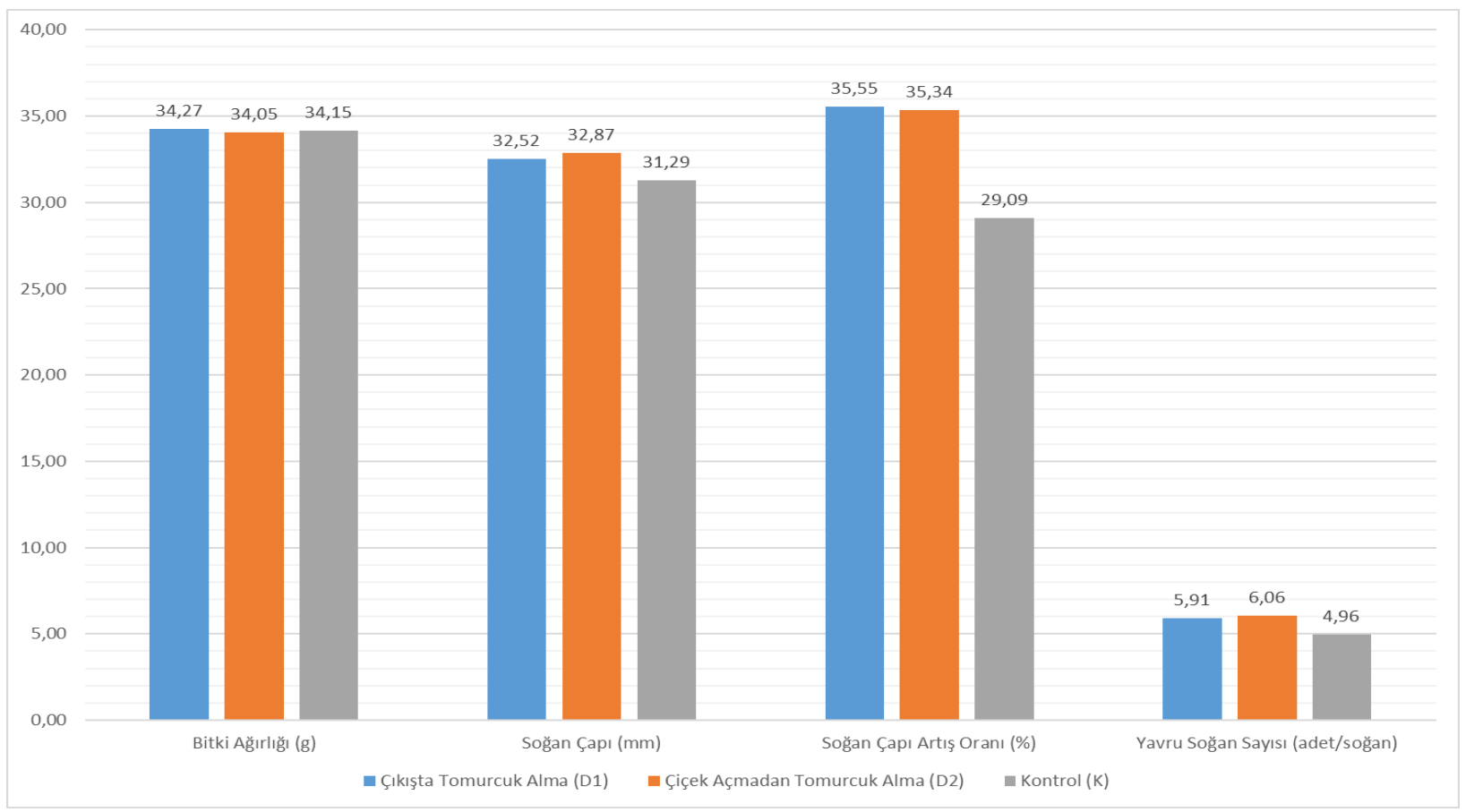

Şekil 6. Çiçek tomurcuğu almanın bitki ağırlığı, soğan çapı ve yavru soğan sayısı üzerine etkisi

İstatiksel bir fark olmamasına karşın en yüksek bitki ağırlığı değeri çıkışta tomurcuk alma (D1) işlemi yapılan uygulamadan elde edilmiştir. Soğan çapı ve soğan çapı artış oranı bakımından çıkışta tomurcuk alma (D1) ve çiçek açmadan tomurcuk alma (D2) uygulamaları kontrol uygulamasına göre daha yüksek değerlere ulaşmıştır. Çiçek tomurcuğu alma işlemi yapılan uygulamalarda soğan çapı artı̧̧ oranı \% 35.34 (D2) ile \% 35.55 (D1) arasında, soğan çapı da 32.52 mm (D1) ile $32.87 \mathrm{~mm}$ (D2) yer almışır (Şekil 6). Kahraman (2016); Beyaz zambak bitkisinde çiçek tomurcuğu almanın bitki gelişine etkilerini incelediği çalışmasında, çiçek tomurcuğu alınan beyaz zambak bitkilerinin soğan çapının kontrole göre daha büyük olduğunu tespit etmiştir. Kahraman (2017); farklı dönemlerde çiçek tomurcuğu almanın Lale gelişimi üzerine etkilerini incelediği çalışmasında, en yüksek soğan çapı değerlerinin çiçek tomurcuklarının çıkışta ve çiçek açmadan önce alındığı uygulamalarda olduğunu belirtmiştir. Üzüm sümbülünde yapılan bu çalışmada ise çiçek tomurcuğu almanın soğan çapı üzerinde istatiksel bir fark oluşturmadığı belirlenmiştir. Çiçek tomurcuğu almanın türler bakımından farklı etkilerinin olduğu söylenebilir. Yavru soğan sayısı yönünden uygulamalar arasında fark önemsiz bulunmuş. Soğan başına en yüksek yavru soğan sayısı kontrol dışındaki D1 (5.91 adet) ve D2 (6.06 adet)'de belirlenmiştir. Kahraman (2016, 2017); beyaz zambak ve lalede yaptığı çiçek tomurcuğu alma uygulamalarında da yavru soğan sayısı bakımından uygulamalar arası herhangi bir fark belirlememiştir. Şekil 7 ve 8.'de denemede büyüme göstermiş ana soğanlar ve yavru soğanlar görülmektedir. Varyans analizi sonucunda; çiçek tomurcuğu alma uygulamalarının yaprak parametreleri üzerine etkisinin önemsiz olduğu tespit edilmiştir.

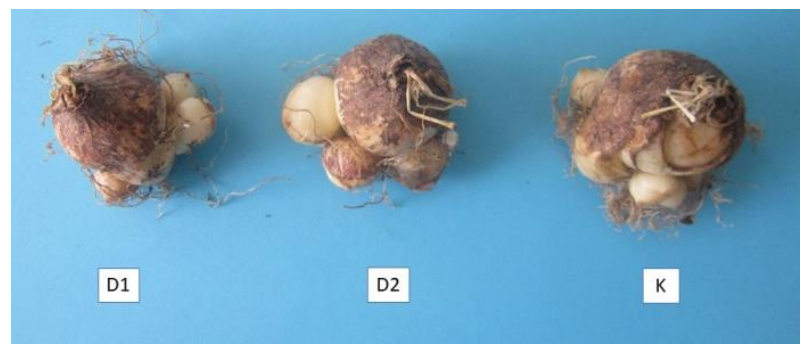

Şekil 7. Çiçek tomurcuğu alma uygulamaları yapılmış bitkilerin soğanları 


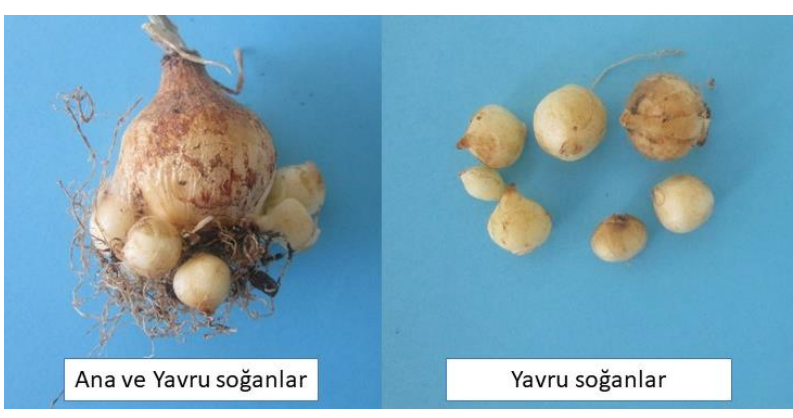

Şekil 8. D2 uygulaması yapılmış ana soğan ve yavru soğanlar

Kahraman (2017) benzer şekilde; Lalede çiçek tomurcuğu almanın yaprak parametreleri üzerine etkisini önemsiz olduğunu ifade etmiştir. Üzüm sümbülünde yaprak sayısı 5.89 ile 6.52 adet arasında, yaprak uzunluğu $49.59 \mathrm{~cm}$ ile $50.93 \mathrm{~cm}$ olmuştur. Çıkışta tomurcuk alma uygulamasında; yaprak eni 7.84 $\mathrm{mm}$, yaprak kalınlığı ise $0.67 \mathrm{~mm}$ gerçekleşmiştir (Şekil 9).

\subsection{Bitki gelişim özellikleri arasındaki ikili ilişkiler}

Üzüm sümbülü bitkisindeki gelişim özellikleri arası ikili ilişkiler Çizelge 1.'de toplu gösterilmiştir. Bitki ağırlığı ile soğan çap1 $(\mathrm{r}=0.530)$ ve yaprak sayısı $(\mathrm{r}=0.392)$ arasındaki pozitif ilişki $(\mathrm{p}=0.01)^{\prime} \mathrm{e}$ göre önemli bulunmuştur. Bitki ağırlığı artışı ile beraber soğan çap1 ve yaprak sayısı değerlerinde artış belirlenmiştir. Soğan çapı ve yaprak sayısı arasında da \% 99 güvenle pozitif bir ilişki tespit edilmiştir $(\mathrm{r}=0.553)$. Bitki ağırlı̆̆ı, soğan çap1 ve yaprak sayısı birlikte artış göstermiştir. Çiçek sapı çapı ve yaprak eni arasında $(\mathrm{p}=0.01)$ 'e göre olumlu ilişki belirlenmiştir. Salkımdaki çiçek sayısının çiçek salkım uzunluğunu pozitif yönde etkilediği saptanmıştır (Çizelge 1).

\section{Sonuç}

Farklı gelişim dönemlerinde çiçek tomurcuğu alma işleminin üzüm sümbülünde bitki gelişimi üzerine etkilerini belirlemek için yürütülen bu çalışmada, farklı gelişim aşamalarda çiçek tomurcuğu alma işlemlerinin soğan gelişimi üzerine etkisinin önemsiz olduğu belirlenmiş̧tir. Soğan çapı ve yavru soğan sayısı bakımından istatiksel bir öneme sahip olmamasına karşın çiçek tomurcuğu alınan uygulamalar kontrole göre daha yüksek çıkmıştır. Bitki ağırlığı, yaprak uzunluğu, yaprak eni ve yaprak kalınlığı gibi toprak üstü parametreleri ise benzerlik göstermiştir.

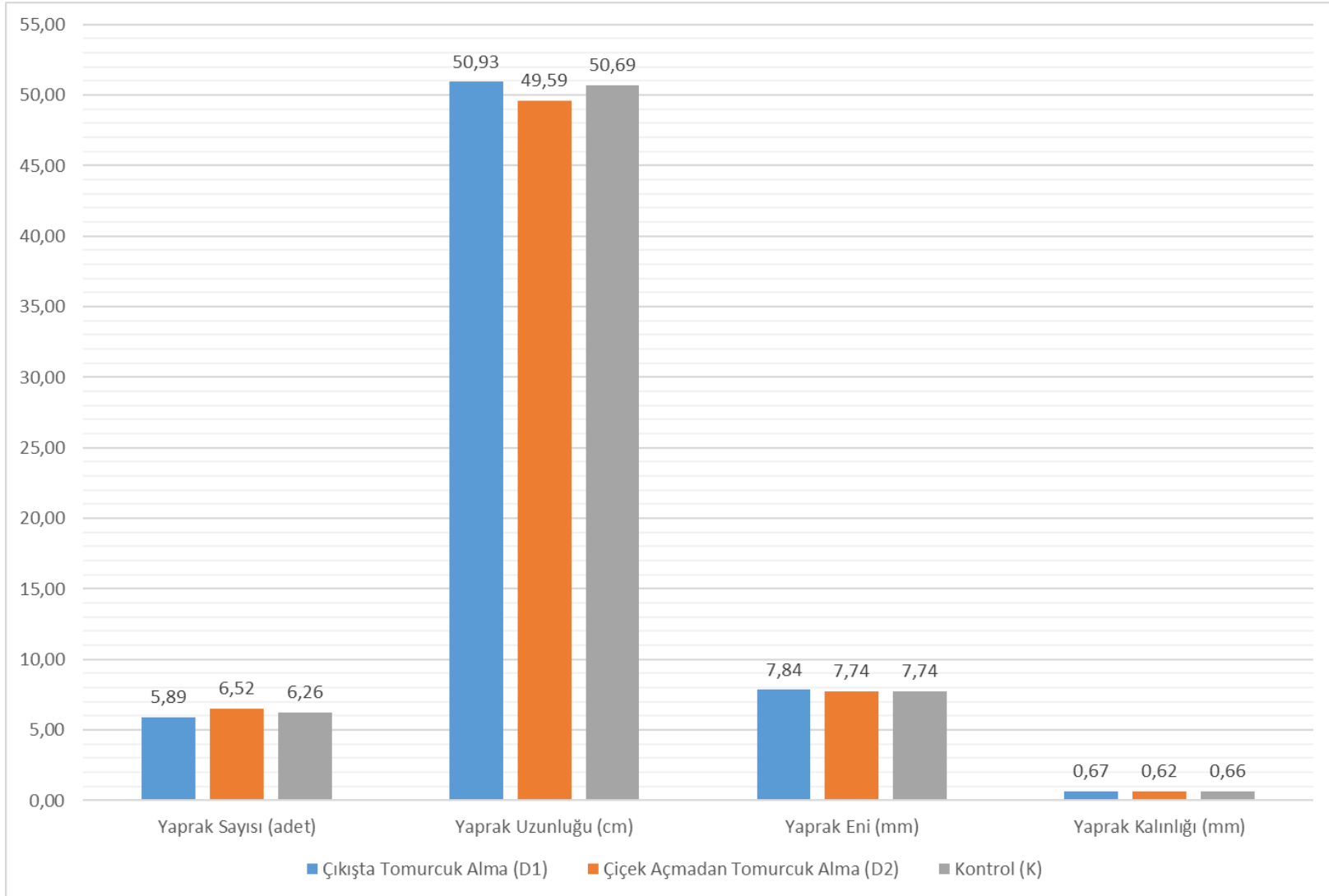

Şekil 9. Çiçek tomurcuğu almanın yaprak özellikleri üzerine etkisi 
Çizelge 1. Bitki gelişim özellikleri arası ikili ilişkiler

\begin{tabular}{|c|c|c|c|c|c|c|c|c|c|c|c|c|}
\hline & 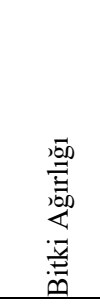 & 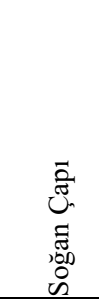 & 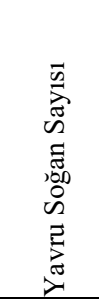 & 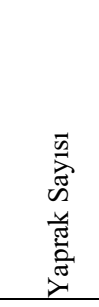 & 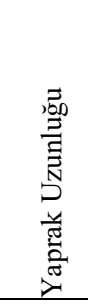 & 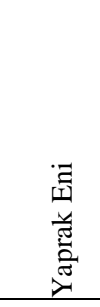 & 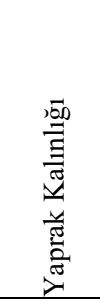 & 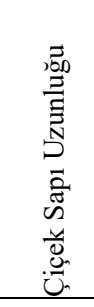 & 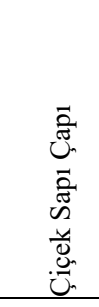 & 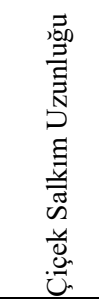 & 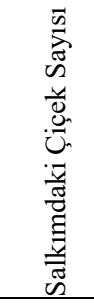 & 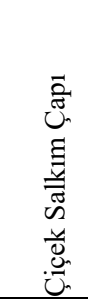 \\
\hline Bitki Ağırlığ1 & 1 & $0.530^{* * *}$ & -0.109 & $0.392^{* *}$ & 0.143 & -0.080 & 0.364 & -0.937 & -0.701 & 0.109 & 0.138 & 0.859 \\
\hline Soğan Çap1 & $0.530^{* *}$ & 1 & -0.051 & $0.553^{* *}$ & 0.079 & -0.237 & 0.577 & -0.751 & -0.401 & 0.457 & 0.482 & 0.620 \\
\hline Yavru Soğan Sayısı & -0.109 & -0.051 & 1 & 0.013 & -0.179 & -0.180 & -0.815 & 0.000 & -0.423 & -0.969 & -0.976 & 0.179 \\
\hline Yaprak Sayısı & $0.392^{* *}$ & $0.553^{* *}$ & 0.013 & 1 & -0.180 & -0.057 & 0.273 & 0.756 & 0.962 & 0.820 & 0.803 & -0.861 \\
\hline Yaprak Uzunluğu & 0.143 & 0.079 & -0.179 & -0.180 & 1 & 0.386 & -0.021 & 0.996 & 0.942 & 0.335 & 0.308 & -0.996 \\
\hline Yaprak Eni & -0.080 & -0.237 & -0.180 & -0.057 & 0.386 & 1 & 0.318 & 0.901 & $0.982^{* *}$ & 0.642 & 0.619 & -0.964 \\
\hline Yaprak Kalınlığ 1 & 0.364 & 0.577 & -0.815 & 0.273 & -0.021 & 0.318 & 1 & -0.126 & 0.306 & 0.931 & 0.941 & -0.054 \\
\hline Çiçek Sapı Uzunluğu & -0.937 & -0.751 & 0.000 & 0.756 & 0.996 & 0.901 & -0.126 & 1 & 0.906 & 0.245 & 0.217 & -0.984 \\
\hline Çiçek Sap1 Çap1 & -0.701 & -0.401 & -0.423 & 0.962 & 0.942 & $0.982^{* *}$ & 0.306 & 0.906 & 1 & 0.632 & 0.609 & -0.967 \\
\hline Çiçek Salkım Uzunluğu & 0.109 & 0.457 & -0.969 & 0.820 & 0.335 & 0.642 & 0.931 & 0.245 & 0.632 & 1 & $0.998^{*}$ & -0.415 \\
\hline Salkımdaki Çiçek Sayısı & 0.138 & 0.482 & -0.976 & 0.803 & 0.308 & 0.619 & 0.941 & 0.217 & 0.609 & $0.998^{*}$ & 1 & -0.388 \\
\hline Çiçek Salkım Çapı & 0.859 & 0.620 & 0.179 & -0.861 & -0.996 & -0.964 & -0.054 & -0.984 & -0.967 & -0.415 & -0.388 & 1 \\
\hline
\end{tabular}

** : \% 99 önemli, * : \% 95 önemli

\section{Kaynaklar}

Avcı, M., 2005. Çeşitlilik ve endemizm açısından türkiye'nin bitki örtüsü. İstanbul Üniversitesi Fen Edebiyat Fakültesi Coğrafya Dergisi, Sayı:13, $27-$ 55.

Kahraman, Ö., 2016. Çiçek tomurcuğu almanın beyaz zambak soğan gelişimi üzerine etkileri. Bahçe:Yalova Atatürk Bahçe Kültürleri Merkez Araştırma Enstitüsü Dergisi, 45:1035-1038.

Kahraman, Ö., 2017. Effects of the picking pedicle at different stages on tulip growth. VIII International Scientific Agriculture Symposium, Proceedings Book, 861-866, October 05-08, Jahorina, Bosnia and Herzegovina.
Özhatay, N., 2013. Türkiye'nin süs bitkileri potansiyeli: doğal monokotil geofitler. V. Süs Bitkileri Kongresi, Cilt:1, 1-12, 06-09 Mayıs, Yalova.

Pamay, B., 2004. Bitki materyali III-park ve bahçe çiçeklerimizin çiçekleri. Orhan Ofset Basımevi, 214 $\mathrm{s}$, İstanbul.

Resmi Gazete. 2017a. Doğal çiçek soğanlarının doğadan toplanması, üretimi ve ihracatına ilişkin yönetmelik. Sayı:30014, 21 Mart Salı.

Resmi Gazete. 2017b. Doğal çiçek soğanlarının 2018 y1lı ihracat listesi hakkında tebliğ (Tebliğ No: 2017/49). 30 Aralık Cumartesi.

Tübives. 2018. Türkiye bitkileri veri servisi. (http://www.tubives.com/index.php?sayfa=1\&tax_id =9106 Erişim Tarihi:11.Temmuz 2018).

Yücel, E. 2002. Çiçekler ve yerörtücüler I. Etam Matbaa Tesisleri, 1. Bask1, 357 s, Eskişehir. 